\title{
Growth of wildtype and mutant $E$. coli strains in minimal media for optimal production of nucleic acids for preparing labeled nucleotides
}

\author{
Chandar S. Thakur • Margaret E. Brown • \\ Jacob N. Sama • Melantha E. Jackson • T. Kwaku Dayie
}

Received: 30 May 2010 /Revised: 23 July 2010 / Accepted: 30 July 2010 / Published online: 21 August 2010

(C) The Author(s) 2010. This article is published with open access at Springerlink.com

\begin{abstract}
Since RNAs lie at the center of most cellular processes, there is a need for synthesizing large amounts of RNAs made from stable isotope-labeled nucleotides to advance the study of their structure and dynamics by nuclear magnetic resonance (NMR) spectroscopy. A particularly effective means of obtaining labeled nucleotides is to harvest these nucleotides from bacteria grown in defined minimal media supplemented with ${ }^{15} \mathrm{NH}_{4} \mathrm{Cl}$ and various carbon sources. Given the high cost of carbon precursors required for labeling nucleic acids for NMR studies, it becomes important to evaluate the optimal growth for commonly used strains under standard minimal media conditions. Such information is lacking. In this study, we characterize the growth for Escherichia coli strains K12, K10zwf, and DL323 in three minimal media with isotopiclabeled carbon sources of acetate, glycerol, and glycerol combined with formate. Of the three media, the LeMasterRichards and the Studier media outperform the commonly used M9 media and both support optimal growth of $E$. coli for the production of nucleotides. However, the growth of all three E. coli strains in acetate is reduced almost twofold compared to growth in glycerol. Analysis of the metabolic pathway and previous gene array studies help to explain this differential growth in glycerol and acetate. These
\end{abstract}

Electronic supplementary material The online version of this article (doi:10.1007/s00253-010-2813-y) contains supplementary material, which is available to authorized users.

C. S. Thakur • M. E. Brown · J. N. Sama • M. E. Jackson •

T. K. Dayie $(\bowtie)$

Department of Chemistry and Biochemistry,

Center for Biomolecular Structure \& Organization,

University of Maryland,

1115 Biomolecular Sciences Bldg (\#296),

College Park, MD 20742-3360, USA

e-mail: dayie@umd.edu studies should benefit efforts to make selective ${ }^{13} \mathrm{C}-{ }^{15} \mathrm{~N}$ isotopic-labeled nucleotides for synthesizing biologically important RNAs.

Keywords Escherichia coli $\cdot \mathrm{K} 12 \cdot \mathrm{K} 10 \mathrm{zwf} \cdot \mathrm{DL} 323$. BL21 · Minimal media $\cdot$ Glycerol $\cdot$ Acetate $\cdot$ Formate

\section{Introduction}

Various methods exist for labeling nucleic acids and proteins with stable isotopes for structural and dynamics studies (Dayie 2008; Hoogstraten and Johnson 2008; Lu et al. 2010). Escherichia coli is a commonly used bacterial host for protein production and for making RNA (Ponchon and Dardel 2007; Ponchon et al. 2009). E. coli can grow in chemically defined minimal media supplemented with ${ }^{15} \mathrm{~N}$ labeled nitrogen and ${ }^{13} \mathrm{C}$-labeled carbon sources. The total cellular RNA obtained from such growth is enzymatically digested to nucleoside monophosphates (NMPs) and the NMPs are rephosphorylated to the nucleoside triphosphates (NTPs). These labeled NTPs then serve as the building blocks for making labeled RNA of any desired sequence using T7 RNA polymerase-based transcription (Milligan and Uhlenbeck 1989; Batey et al. 1992; Batey et al. 1995).

Previously, ${ }^{13} \mathrm{C}$ or ${ }^{13} \mathrm{C} /{ }^{15} \mathrm{~N}$ labeled nucleotides were produced by growing the bacteria Methylophilus methylotrophus (Batey et al. 1992) or Methylobacterium extorquens (Hines et al. 1994) on ${ }^{13} \mathrm{C}$-methanol as the most economical source of ${ }^{13} \mathrm{C}$-labeled carbon. At that time, the use of these bacteria that grow on methanol had the singular advantage of reduced cost over E. coli (Batey et al. 1995), but it is no longer advantageous for a number of reasons. First, isotopic scrambling occurs during biosynthesis and precludes the incorporation of site-specific isotopic labels using metha- 
nol. Second, the methylophiles have significantly lower ribonucleotide content per gram of cells (Byron 1975) resulting in yields of NMPs from M. methylotrophus that are $42 \%$ of the amount of NMPs obtainable from $E$. coli (Batey et al. 1992). Third, ${ }^{13} \mathrm{C}$-labeled methanol is no longer the least expensive isotopic source for labeling carbon in biomolecules; ${ }^{13} \mathrm{C}$-labeled sodium acetate can fulfill this role (Table 1). Finally, on per gram of carbon ratio, ${ }^{13} \mathrm{C}$-2-glycerol is now comparable in price to methanol; labeled glucose still remains expensive on a per mole carbon basis (Table 1). Therefore E. coli is now favored over methylobacteria for incorporation of ${ }^{13} \mathrm{C}$ and ${ }^{15} \mathrm{~N}$ labels.

In addition to these cost considerations, a number of $E$. coli strains offer the potential for uniform and alternate sitespecific ${ }^{13} \mathrm{C}$ isotopic labeling. For example, the growth of wildtype $E$. coli strain $\mathrm{K} 12$ on sodium ${ }^{13} \mathrm{C}$-2-acetate $\left({ }^{13} \mathrm{CH}_{3} \mathrm{COONa}\right)$ leads to $>90 \%$ labeling efficiency at the $\mathrm{C} 5$ and $\mathrm{C} 6$ carbon positions in the pyrimidine rings and at the $\mathrm{C} 2, \mathrm{C} 5$, and $\mathrm{C} 8$ carbon positions within the purine rings (Hoffman and Holland 1995). Similarly, growth on ${ }^{13} \mathrm{C}-1$, 3-glycerol yields $\sim 90 \%{ }^{13} \mathrm{C}$ isotopic enrichment at the $\mathrm{C} 5$ position of pyrimidines for mutant E. coli strain DL323 deficient in two tricarboxylic acid (TCA) cycle enzymes: succinate dehydrogenase (sdh) and malate dehydrogenase (mdh). Likewise, growth of DL323 on ${ }^{13} \mathrm{C}$-2-glycerol yields $\sim 90 \%{ }^{13} \mathrm{C}$ isotopic enrichment at the $\mathrm{C} 6$ position of pyrimidines (Johnson et al. 2006). In contrast, growth on ${ }^{13} \mathrm{C}$-2-glycerol labels not only the $\mathrm{C} 2{ }^{\prime}(\sim 90 \%)$ and $\mathrm{C}^{\prime}$ $(\sim 90 \%)$ ribose positions, but also the $\mathrm{C} 5$ and $\mathrm{C} 6$ positions of pyrimidines mutually exclusively for another E. coli strain K10-1516 (hereafter referred to as K10zwf). K10zwf is deficient in the glucose-6-phosphate dehydrogenase enzyme. Unlike K12 and DL323, the growth of K10zwf on ${ }^{13} \mathrm{C}$-2-glycerol does not introduce significant multiplet splitting due to ${ }^{1} \mathrm{~J}_{\mathrm{C} 5 \mathrm{C} 6}$ scalar coupling in the pyrimidine ring (Johnson et al. 2006; Hoogstraten and Johnson 2008;

Table 1 Cost in US dollars/gram of common carbon sources for making labeled NTPs using E. coli (from CIL and Sigma for bulk purchases of $>20 \mathrm{~g}$ )

\begin{tabular}{lcc}
\hline Labeled compounds & Price $(\$) / \mathrm{g}$ & Price $\left(\$ 100^{*}\right) / \mathrm{g}$ mole \\
\hline Sodium ${ }^{13} \mathrm{C}-1$-Acetate & 22 & 18 \\
Sodium ${ }^{13} \mathrm{C}-2$-Acetate & 25 & 21 \\
${ }^{13} \mathrm{C}-$ Methanol & 88 & 30 \\
Sodium ${ }^{13} \mathrm{C}-1,2$-Acetate & 47 & 39 \\
Sodium ${ }^{13} \mathrm{C}-$ Formate & 63 & 43 \\
${ }^{13} \mathrm{C}-2-$ Glycerol & 100 & 92 \\
${ }^{13} \mathrm{C}-1,2,3,4,5,6-$ Glucose & 68 & 123 \\
${ }^{13} \mathrm{C}-1,3-$-Glycerol & 158 & 158 \\
\hline
\end{tabular}

Dayie and Thakur 2010). Furthermore, addition of ${ }^{13} \mathrm{C}$ labeled sodium formate to the growth media containing unlabeled glucose leads to the selective labeling of the C8 position within the purine ring (Latham et al. 2005). We recently demonstrated that spiking the growth medium with ${ }^{13} \mathrm{C}$ labeled formate increases the number of sites selectively enriched in K10zwf (Dayie and Thakur 2010). For cost effectiveness and selective carbon labeling, E. coli is, therefore, likely to remain an organism of choice for incorporation of isotopic labels.

Since large quantities of labeled NTPs are needed for most biophysical studies such as nuclear magnetic resonance (NMR), it is critical to find conditions that achieve optimal nucleic acid yield. Recently, Paliy and Gunasekera demonstrated that the commonly used M9 media did not support optimal growth of E. coli BL21. Rather, when ferrous sulfate was added to the M9 media and the concentration of phosphate in this media was increased to approximate the LeMaster-Richards (LMR) media (LeMaster and Richards 1982), the cell density in the stationary phase tripled (Paliy and Gunasekera 2007). Studier also showed that minimal media containing 50 $100 \mathrm{mM}$ phosphate was optimal for protein and plasmid production (Studier 2005). Based on these observations, we hypothesize that the Studier and LeMaster-Richards but not M9 media will be optimal for nucleic acid production.

Therefore, in this work we characterize the growth of three $E$. coli strains in three different minimal media for production of specifically labeled nucleotides: M9, LMR, and Studier phosphate buffer (SPG; LeMaster and Richards 1982; Sambrook and Russell 2001; Studier 2005). We find that both the LMR and SPG media outperform the traditional M9 media, and growth of $E$. coli in both LMR and SPG provide similar amounts of genomic DNA and RNA for subsequent hydrolysis to nucleoside monophosphates. In turn, the nucleosides triphosphates can be used to transcribe labeled RNA and DNA of any desired sequence.

\section{Material and methods}

\section{Bacterial strains}

The strains used in this work were obtained from the following sources: Dr. Paliy kindly provided the wildtype K12 NCM3722 (Soupene et al. 2003); the Coli Genetic Stock Center (CGSC) was the source of the wildtype K12 strain (Clowes 1968) (CGSC \# 4401: $\mathrm{F}^{+}$), the mutant strain DL323 (LeMaster and Kushlan 1996) (CGSC \# 7538: F sdh-1, $\lambda^{-}$, mdh-2, rph-1) and the mutant strain K10-15-16 (CGSC \# 4858 Hfr fhuA22, zwf-2, relA1, $T_{2}^{R}$, pfk-10). 
Isotopes

All labeled compounds were purchased from Cambridge Isotope Laboratory (Andover, MA, USA) and Isotec-Sigma Aldrich (Miamisburg, OH, USA) with the following isotopic enrichments: sodium ${ }^{13} \mathrm{C}$-2-acetate $(99 \%),{ }^{13} \mathrm{C}$-2-glycerol (99\%), ${ }^{13} \mathrm{C}$-1,3-glycerol (99\%), sodium ${ }^{13} \mathrm{C}$-formate $(99 \%)$ and ${ }^{15} \mathrm{~N}-\left(\mathrm{NH}_{4}\right)_{2} \mathrm{SO}_{4}(99 \%)$.

\section{Stock solutions}

The stock solutions required for bacterial growth were prepared using distilled and deionized heat-sterilized water. The $10,000 \times$ trace metals solution was prepared in $10 \mathrm{ml}$ aliquots containing $5 \mathrm{~mL}$ of $0.1 \mathrm{M} \mathrm{FeCl}_{3} \cdot 6 \mathrm{H}_{2} \mathrm{O}$ dissolved in $\sim 0.1 \mathrm{M} \mathrm{HCl}, 0.2 \mathrm{ml}$ of $1 \mathrm{M} \mathrm{CaCl} 2,0.1 \mathrm{~mL}$ of $1 \mathrm{M} \mathrm{MnCl}_{2} \cdot 4 \mathrm{H}_{2} \mathrm{O}, 0.1 \mathrm{~mL}$ of $1 \mathrm{M} \mathrm{ZnSO}_{4} \cdot 7 \mathrm{H}_{2} \mathrm{O}, 0.1 \mathrm{~mL}$ of $0.2 \mathrm{M} \mathrm{CoCl} 2 \cdot 6 \mathrm{H}_{2} \mathrm{O}, 0.2 \mathrm{~mL}$ of $0.1 \mathrm{M} \mathrm{CuCl}_{2} \cdot 2 \mathrm{H}_{2} \mathrm{O}$, $0.1 \mathrm{~mL}$ of $0.2 \mathrm{M} \mathrm{NiCl} \mathrm{N}_{2} \cdot 6 \mathrm{H}_{2} \mathrm{O}, 0.2 \mathrm{~mL}$ of $0.1 \mathrm{M} \mathrm{Na}_{2} \mathrm{MoO}_{4} \cdot 5 \mathrm{H}_{2} \mathrm{O}, 0.2 \mathrm{~mL}$ of $0.1 \mathrm{M} \mathrm{Na} \mathrm{SeO}_{3} \cdot 5 \mathrm{H}_{2} \mathrm{O}$, $0.2 \mathrm{~mL}$ of $0.1 \mathrm{M} \mathrm{H}_{3} \mathrm{BO}_{3}, \mathrm{FeSO}_{4} \cdot 7 \mathrm{H}_{2} \mathrm{O}$ (Tyler et al. 2005). All stock solutions of individual metals except acidified $\mathrm{FeCl}_{3} \cdot 6 \mathrm{H}_{2} \mathrm{O}$ were heat-sterilized and the trace metals solutions were wrapped in aluminum foil and stored at $25^{\circ} \mathrm{C}$ until use.

\section{Media for bacterial growth}

Luria Bertani, M9, LMR, and SPG minimal media were prepared as described (LeMaster and Richards 1982; Sambrook and Russell 2001; Paliy et al. 2003; Studier 2005) with compositions shown in Supplementary Table 1. For the optimization step, each media was supplemented with varying $(0.05-5 \% \mathrm{w} / \mathrm{v})$ carbon source of sodium acetate, glycerol, glycerol combined with sodium formate, and varying $(0.01-5 \% \mathrm{w} / \mathrm{v})$ nitrogen source of ammonium sulfate. We are interested in finding optimal conditions for growth in acetate because labeled acetate can be used optimally for uniform labeling using K12. However, K12 is not optimal for site-specific labeling using glycerol and formate because of scrambling of the label in the ribose and nucleobase moieties. However, K10zwf and DL323 are ideal for site-specific labeling and so we present data for these two strains using either glycerol alone or glycerol with formate. But for $\mathrm{K} 12$, we present data for only acetate.

\section{Optimization of growth conditions}

The growth of each bacterial strain was optimized for the highest production of biomass per input gram of carbon source by growing 10 and $500 \mathrm{ml}$ cultures with increasing amounts of each carbon source.
For 5-10 $\mathrm{ml}$ starter cultures of each E. coli strain (DL323, K10zwf, K12), aliquots from glycerol stocks stored at $-80^{\circ} \mathrm{C}$ were grown overnight at $270 \mathrm{rpm}$ and $37^{\circ} \mathrm{C}$ in SPG media containing the following: $25 \mathrm{mM}$ $\left(\mathrm{NH}_{4}\right)_{2} \mathrm{SO}_{4}, 50 \mathrm{mM} \mathrm{KH}_{2} \mathrm{PO}_{4}, 50 \mathrm{mM} \mathrm{Na} \mathrm{HPO}_{4}$ and $2 \mathrm{mM} \mathrm{MgSO}_{4}$. This $\mathrm{SPG}$ media was supplemented with $0.4 \% w / v$ glycerol and $0.2 \times$ trace metal solution. The overnight culture was pelleted at $3,000 \mathrm{rpm}$ at $4^{\circ} \mathrm{C}$ for $5 \mathrm{~min}$, the pellets were washed twice with $1 \times$ phosphatebuffered saline and then gently resuspended in $10 \mathrm{ml}$ of SPG media. About $50 \mu$ of the dissolved pellet was added to each of the conditions tested in a total volume of $10 \mathrm{ml}$. By starting with an $\mathrm{OD}_{600}$ of 0.05 for all resuspended pellets, highly reproducible results with consistent lag times were obtained. Unless noted otherwise, at least three independent experiments were carried out for all three strains in all growth conditions tested.

\section{Results}

RNA is estimated to be $20 \%$ of the dry weight of rapidly dividing E. coli cells (Feist et al. 2007). By isolating total nucleic acids from bacterial cells grown on isotopically labeled precursors, labeled monomers needed for making RNA of any desired sequence can be synthesized in very large quantities. Particularly in the area of RNA biophysics, custom made nucleotides that are site-selectively enriched with ${ }^{13} \mathrm{C}$ and/or ${ }^{15} \mathrm{~N}$ stable isotopes are desirable for tackling the structures of large RNAs (Dayie 2008; Lu et al. 2010). Therefore, the judicious choice of E. coli strains and labeled precursors is important in achieving those goals.

Previous work by Hoffman and Holland (1995) and Nikonowicz (2001) established that wildtype E. coli strains grown on acetate produce labeled nucleotides useful for making RNA for NMR studies. Recent work by Hoogstraten et al. also demonstrated that glycerol is a useful complement to acetate for site-specific labeling of nucleotides for biophysical studies using mutant E. coli strains (Johnson et al. 2006; Johnson and Hoogstraten 2008). Given the high cost of most labeled precursors, it is important to obtain optimal growth conditions for these $E$. coli strains in various commonly used media.

Thus to ascertain optimal growth conditions, we grew $E$. coli K12-NCM3722 (Soupene et al. 2003), K10zwf (Fraenkel 1968), and DL323 (LeMaster and Kushlan 1996) in three different minimal media supplemented with two different carbon sources.

K12 strain grew well on glycerol with a lag phase of $\sim 1 \mathrm{~h}$ in all three media (LMR, SPG, and M9) followed by normal Sshaped growth (Table 2, Fig. 1) and a doubling time of $\sim 1.3-$ $1.7 \mathrm{~h}$. In addition, the maximum cell optical density was 
Table 2 The maximum optical density $\left(\mathrm{OD}_{600}\right)$, lag phase (h), and doubling time (h) of three E. coli strains K10zwf, K12, and DL323 in aerobic batch cultures in three different minimal media of LMR, SPG, and M9

\begin{tabular}{|c|c|c|c|c|c|c|}
\hline Strain & Carbon Source & Media & Max (OD600) & Lag Phase (h) & DT (h) & References \\
\hline K12 & Glycerol & SPG & $2.3 \pm 0.1$ & 1 & $1.4 \pm 0.04$ & This work \\
\hline K12 & Glycerol & LMR & $2.4 \pm 0.1$ & 1 & $1.3 \pm 0.1$ & This work \\
\hline K12 & Glycerol & M9 & $1.9 \pm 0.1$ & 1 & $1.7 \pm 0.1$ & This work \\
\hline K12 & Glycerol & M9 & 0.83 & 1 & $(2.2)$ & Paliy and Gunasekera 2007 \\
\hline$M G 1655$ & Glycerol & M9 & $n / a$ & $n / a$ & (1.3) & Liu et al. 2005 \\
\hline$M C 4100$ & Glycerol & M9 & $n / a$ & $n / a$ & (1) & Oh and Liao 2000 \\
\hline$K-10$ & Glucose & M9 & $n / a$ & $n / a$ & (1) & Fraenkel 1968 \\
\hline$M G 1655$ & Glucose & M9 & $n / a$ & $n / a$ & $(0.9)$ & Canonaco et al. 2001 \\
\hline$M G 1655$ & Glucose & M9 & $n / a$ & $n / a$ & $(0.7)$ & Liu et al. 2005 \\
\hline$M G 1655$ & Glucose & M9 & $n / a$ & $n / a$ & (1.1) & Nicolas et al. 2007 \\
\hline$M C 4100$ & Glucose & M9 & $n / a$ & $n / a$ & $(0.7)$ & Oh and Liao 2000 \\
\hline K12 & Acetate & SPG & $1.6 \pm 0.1$ & $4 \pm 1$ & $0.9 \pm 0.1$ & This work \\
\hline K12 & Acetate & LMR & $1.7 \pm 0.1$ & $4 \pm 1$ & $1 \pm 0.2$ & This work \\
\hline K12 & Acetate & M9 & $1.1 \pm 0.1$ & $5 \pm 1$ & $3.1 \pm 0.6$ & This work \\
\hline K12 & Acetate & M9 & 0.85 & 5 & (3.4) & Paliy 2007 \\
\hline$M G 1655$ & Acetate & M9 & $n / a$ & $n / a$ & (3.3) & Liu et al. 2005 \\
\hline$B W 25113$ & Acetate & M9 & $n / a$ & $n / a$ & (3.5) & Zhao et al. 2004 \\
\hline$M C 4100$ & Acetate + ariginine & M9 & $n / a$ & $n / a$ & $(2.1)$ & Oh et al. 2002 \\
\hline MC4100 & Acetate & M9 & $\mathrm{n} / \mathrm{a}$ & $\mathrm{n} / \mathrm{a}$ & $(2.3)$ & Oh and Liao 2000 \\
\hline K10zwf & Glycerol & SPG & $1.9 \pm 0.1$ & $<2$ & $1.6 \pm 0.1$ & This work \\
\hline K10zwf & Glycerol & LMR & $2.2 \pm 0.1$ & $<2$ & $1.2 \pm 0.1$ & This work \\
\hline K10zwf & Glycerol & M9 & $1.5 \pm 0.1$ & $<2$ & $1.5 \pm 0.1$ & This work \\
\hline$Z w f-$ & Glucose & M9 & $n / a$ & $n / a$ & (1.1) & Fraenkel 1968 \\
\hline$Z w f-$ & Glucose & M9 & $n / a$ & $n / a$ & (1) & Nicolas et al. 2007 \\
\hline$Z w f-$ & Glucose & M9 & $n / a$ & $n / a$ & $(1.2)$ & Nicolas et al. 2007 \\
\hline$Z w f-$ & Glucose & M9 & $n / a$ & $n / a$ & (1) & Rowley et al. 1991 \\
\hline K10zwf & Acetate & SPG & $1.9 \pm 0.1$ & $4 \pm 1$ & $2.1 \pm 0.3$ & This work \\
\hline K10zwf & Acetate & LMR & $1.8 \pm 0.1$ & $4 \pm 1$ & $2.3 \pm 0.3$ & This work \\
\hline K10zwf & Acetate & M9 & $1.0 \pm 0.1$ & $6 \pm 1$ & $2.4 \pm 0.2$ & This work \\
\hline$K 10-1516$ & Acetate & M9 & $n / a$ & $n / a$ & (4) & Rowley et al. 1991 \\
\hline K10-1516 & Acetate & M9 & $n / a$ & $n / a$ & (3.5) & Zhao et al. 2004 \\
\hline DL323 & Glycerol & SPG & $2.2 \pm 0.1$ & $\leq 1$ & $1.6 \pm 0.03$ & This work \\
\hline DL323 & Glycerol & LMR & $2.7 \pm 0.1$ & $\leq 1$ & $1.7 \pm 0.1$ & This work \\
\hline DL323 & Glycerol & M9 & $2.2 \pm 0.2$ & $\leq 1$ & $1.9 \pm 0.1$ & This work \\
\hline$s d h-/ m d h^{-}$ & Glucose & M9 & $n / a$ & $n / a$ & (1.4) & Fischer and Sauer 2003 \\
\hline DL323 & Acetate & SPG & $1.6 \pm 0.1$ & $7 \pm 1$ & $1.3 \pm 0.1$ & This work \\
\hline DL323 & Acetate & LMR & $1.5 \pm 0.1$ & $10 \pm 1.5$ & $1.3 \pm 0.1$ & This work \\
\hline DL323 & Acetate & M9 & $0.1 \pm 0.1$ & $>30$ & - & This work \\
\hline$m d h$ & Acetate & M9 & No growth & & & Hansen and Juni 1979 \\
\hline
\end{tabular}

These media are supplemented with $0.2 \%$ glycerol or $0.3 \%$ acetate. The values are shown as arithmetic mean \pm standard error of the mean $(n=3)$. Also shown, in italics and for comparison, are previous measurements on various $E$. coli strains and media

slightly higher in LMR and SPG ( 2.4) than in M9 $(\sim 1.9)$ media. With acetate as the sole carbon source in M9, the growth of K12 is reduced to $\sim 0.6$ times the maximum cell optical density observed for the growth in glycerol. The doubling time remains comparable to that observed in glycerol for LMR and SPG media, yet it is $2-3$ times the growth observed in acetate M9 media (Table 2). Furthermore, the lag phase quadruples when using acetate as the carbon source compared to glycerol for all three media. These observations are similar to those 
Fig. 1 The maximum optical density of various $E$. coli strains grown in aerobic batch culture in Studier (SPG), LeMaster-Richards (LMR), and common M9 (M9) media supplemented with glycerol or acetate as carbon sources. a The maximum optical density of $E$. coli $\mathrm{K} 12$ aerobic batch culture in SPG, LMR, and M9 minimal media supplemented with $0.2 \%$ glycerol as carbon source. b The maximum optical density of $E$. coli $\mathrm{K} 12$ aerobic batch culture in SPG, LMR and M9 minimal media supplemented with $0.3 \%$ acetate as carbon source. c The maximum optical density of $E$. coli $\mathrm{K} 10 \mathrm{zwf}$ aerobic batch culture in SPG, LMR and M9 minimal media supplemented with $0.2 \%$ glycerol as carbon source. d The maximum optical density of $E$. coli K10zwf aerobic batch culture in SPG, LMR and M9 minimal media supplemented with $0.3 \%$ acetate as carbon source. e The maximum optical density of E. coli DL323 aerobic batch culture in SPG, LMR and M9 minimal media supplemented with $0.2 \%$ glycerol as carbon source. $f$ The maximum optical density of $E$. coli DL323 aerobic batch culture in M9 minimal media supplemented with $0.3 \%$ acetate as carbon sources. We provide data for DL323 growth in only M9 medium because we found that growth of DL323 gave consistent results in M9 media, whereas growth on SPG and LMR were erratic. We are currently investigating the cause of this
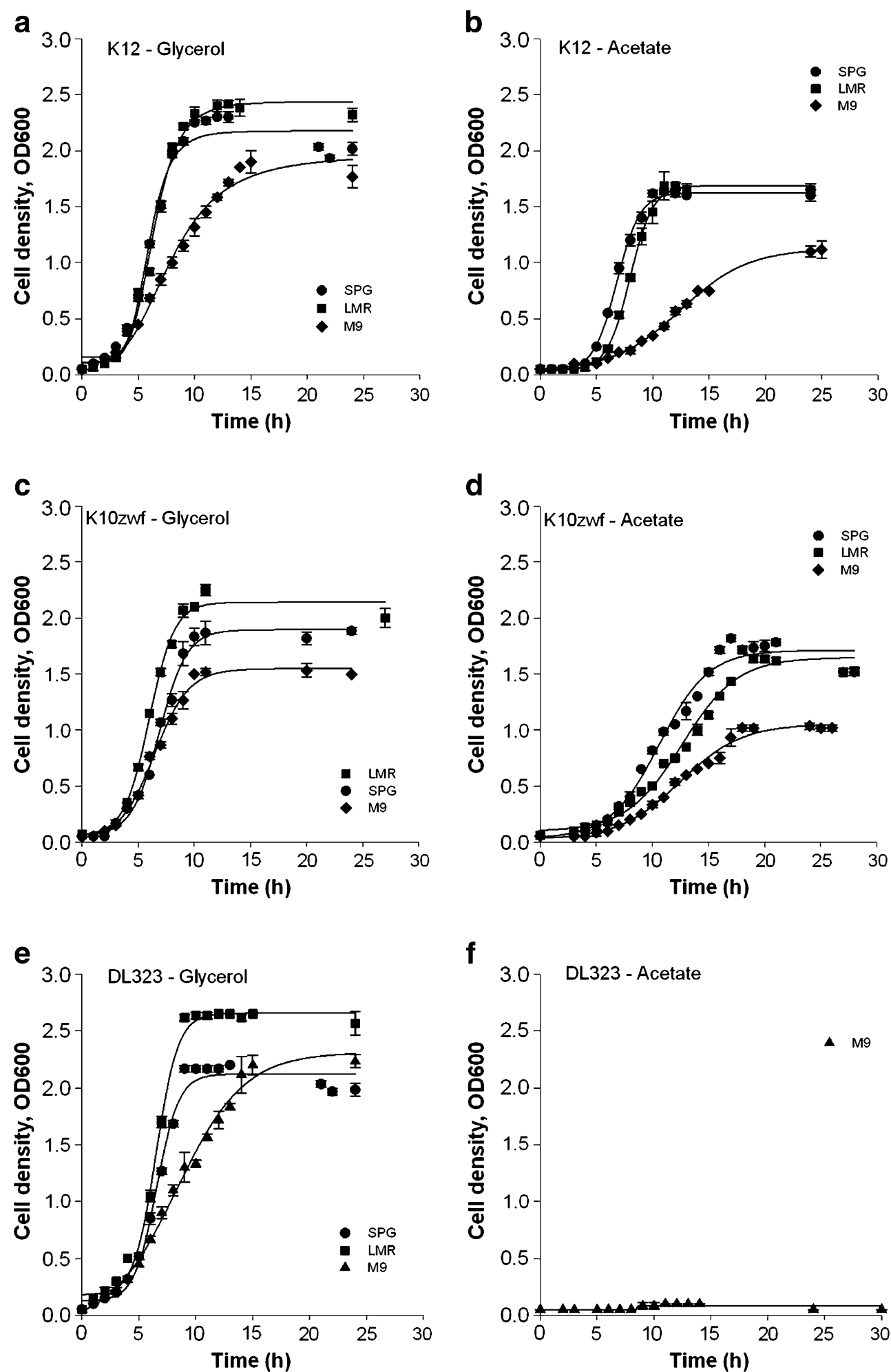

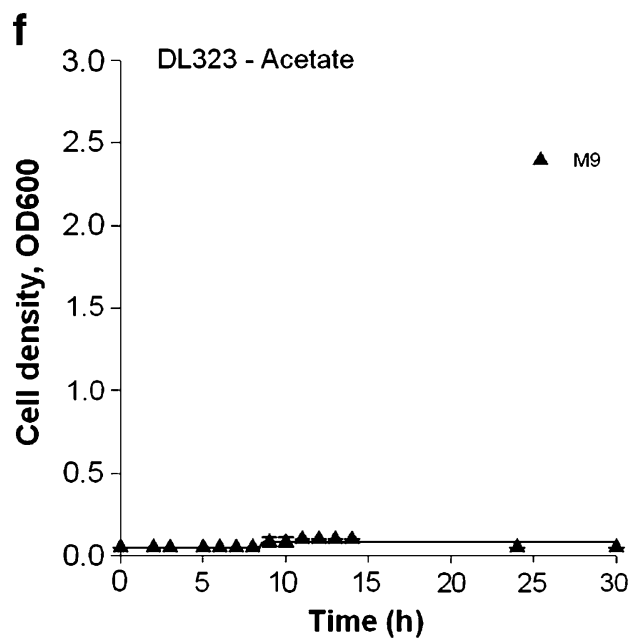

reported for the growth of $\mathrm{K} 12$ in acetate media that also exhibited a lag time of $\sim 5 \mathrm{~h}$ and a doubling time of $\sim 3 \mathrm{~h}$ (Paliy and Gunasekera 2007). Thus, the growth of K12 in M9 media appears crippled compared to growth in SPG and LMR media using either glycerol or acetate as the sole carbon source.
Similar to K12, the K10zwf strain grew well on glycerol with lag phase of $\sim 1 \mathrm{~h}$ in all three media (LMR, SPG, and M9) followed by normal S-shaped growth (Table 2, Fig. 1) and a doubling time of $\sim 1.4 \mathrm{~h}$. The maximum cell optical density was slightly higher in LMR and SPG (1.9-2.2) than in M9 (1.5) media. As observed with the growth of K12 in 
acetate M9, the growth of K10zwf is reduced to $\sim 0.7$ times the maximum cell optical density observed for the growth in glycerol. Again, the doubling time for growth in acetate is $~ 1.3-2$ times that in glycerol (Table 2), and the lag phase is two to three times greater in acetate compared to that in glycerol for all three media. In agreement with our observations, previous studies on K10zwf, mostly done in glucose, indicate that the doubling time is comparable to what is observed in glycerol, but almost two times faster than what is observed in acetate (Table 2).

DL323 also grew considerably well on glycerol with a lag phase of $\sim 1 \mathrm{~h}$ and doubling time of $\sim 1.5 \mathrm{~h}$ in all three media (LMR, SPG, and M9) followed by normal S-shaped growth (Fig. 1). Unlike K10zwf and K12, DL323 did not grow in acetate-based M9 media for up to $30 \mathrm{~h}$. On the whole, the growth of DL323 in glycerol is similar in lag phase and doubling time to that of K12 and K10zwf in LMR and SPG, but this growth is completely impaired in acetate M9 buffer (Fig. 1, Table 2).

In addition to characterizing how well each $E$. coli strain grows in various media, an equally important aspect of working out optimal conditions for growth is finding the required amount of carbon and nitrogen sources needed for favorable growth. The growth of all three $E$. coli strains were optimized by growing $500 \mathrm{ml}$ cultures containing varying acetate concentrations of $0.05-5 \% \mathrm{w} / \mathrm{v}$ and glycerol concentrations of $0.1-10 \% w / v$ (in triplicate), as shown in Fig. 2. The optimal growth for K12 appears centered on $0.3-1 \% w / v$ acetate. For K10zwf and DL323 this growth is centered on $0.2 \% \mathrm{w} / \mathrm{v}$ glycerol. While this optimum falls sharply for the growth of $\mathrm{K} 12$ in acetate, it is slightly broader for DL323 and K10zwf grown in glycerol (Fig. 2a). K10zwf and DL323 strains grow in sodium formate (in a glycerol background) with broad optima of $~ 0.01-0.25 \% \mathrm{w} / \mathrm{v}$; so that a spike of $\sim 0.02 \%$ sodium formate is sufficient to support growth in K10zwf and DL323 (Fig. 2b). Finally, optimization of the amount of nitrogen source using 0.05 $0.5 \% \mathrm{w} / \mathrm{v}$ for $\left(\mathrm{NH}_{4}\right)_{2} \mathrm{SO}_{4}$ indicated that below $0.1 \%$ $\left(\mathrm{NH}_{4}\right)_{2} \mathrm{SO}_{4}$ the growth of K10zwf and DL323 on SPG glycerol media was slightly limiting, and both strains achieve a broad growth optimum centered on $0.1-0.3 \%$. For this work, $0.2 \%$ was selected. For K12 grown in SPG acetate media, this optimum increases only slightly with ammonium ion concentration over the ranges tested (Fig. 2c).

The maximum optical cell density is a good indicator of overall cell growth, but it does not directly report on the amount of ribonucleoside monophosphates made, which is the ultimate goal of growing cell cultures to make labeled ribonucleotides. To ascertain how much of the cell mass is ribonucleotides, we performed a nuclease P1 digest monitored by UV, agarose denaturing gel, and direct carbon and two-dimensional NMR spectroscopy. For some of the growth conditions discussed previously, the ratio of the
rNMP/dNMP was quantified (Table 3). Glycerol-based LMR media achieves a slightly higher cell mass density than glycerol-based SPG media for the growth of DL323 (Fig. 1c) and the corresponding yield of ribonucleotides are also lower for growth in the glycerol-based SPG media (Table 3). Not surprising then, the ratio of the rNMP:dNMP is higher for LMR compared to SPG media for growth of $E$. coli DL323. The growth of K12 in SPG acetate media gives the lowest yield of $1.6 \mathrm{~g}$ of wet weight biomass and the lowest rNMP/dNMP ratio of less than 2. K10zwf, on the other hand, had the highest rNMP:dNMP ratio of 6.7-7.2 and yield of total rNMPs of $50-67.8 \mathrm{mg} / \mathrm{L}$ culture in SPG glycerol media.

\section{Discussion}

For many biophysical analyses of biomolecules, milligram quantities of these biopolymers are frequently needed. Particularly, the ability to make RNA and proteins labeled with ${ }^{13} \mathrm{C}$ and ${ }^{15} \mathrm{~N}$ isotopes is critical for solving the solution structures and probing the dynamics and binding of RNAs and proteins. To synthesize the milligram quantities of labeled materials required for such work, the cost involved can become prohibitive. The cost of labeled carbon is the major component of the overall cost for ${ }^{13} \mathrm{C} /{ }^{15} \mathrm{~N}$ labeling. Therefore, we have evaluated the conditions under which some of the commonly used E. coli strains (K12, K10zwf, and DL323) grow optimally in three minimal media compositions with isotopic-labeled carbon sources of acetate, glycerol, and glycerol combined with formate. Our results substantiate our hypothesis that both the LMR and the SPG media surpass the commonly used M9 media, and both support growth of E. coli in the production of nucleotides. Compared to glycerol, growth in acetate media is substantially reduced.

The overall diminished growth in acetate compared to that in glucose or glycerol is not unexpected given many of the genes correlated with growth rate in the cell are substantially downregulated in E. coli grown in acetate as the sole carbon source (Fig. 3; Oh et al. 2002).

The growth characteristics of the zwf mutant are comparable to the K12 wildtype and can be rationalized similarly by consideration of the central metabolic pathway in E. coli. In the $z w f$ mutant, the glucose-6-phosphate dehydrogenase gene is deleted and the activity of the enzyme is not detectable in crude cell-free extracts (Zhao et al. 2004). Interestingly, even though the carbon flux through the oxidative pentose phosphate pathway to the non-oxidative pentose phosphate pathway (no-PPP) is blocked in the $z w f$ mutant, this flux is re-routed through the reverse no-PPP. Hence, relative to the wildtype, zwf mutants grown on glucose direct $20 \%$ more carbon flux through the first step of the Embden-Meyerhof pathway and about 14-26\% more 

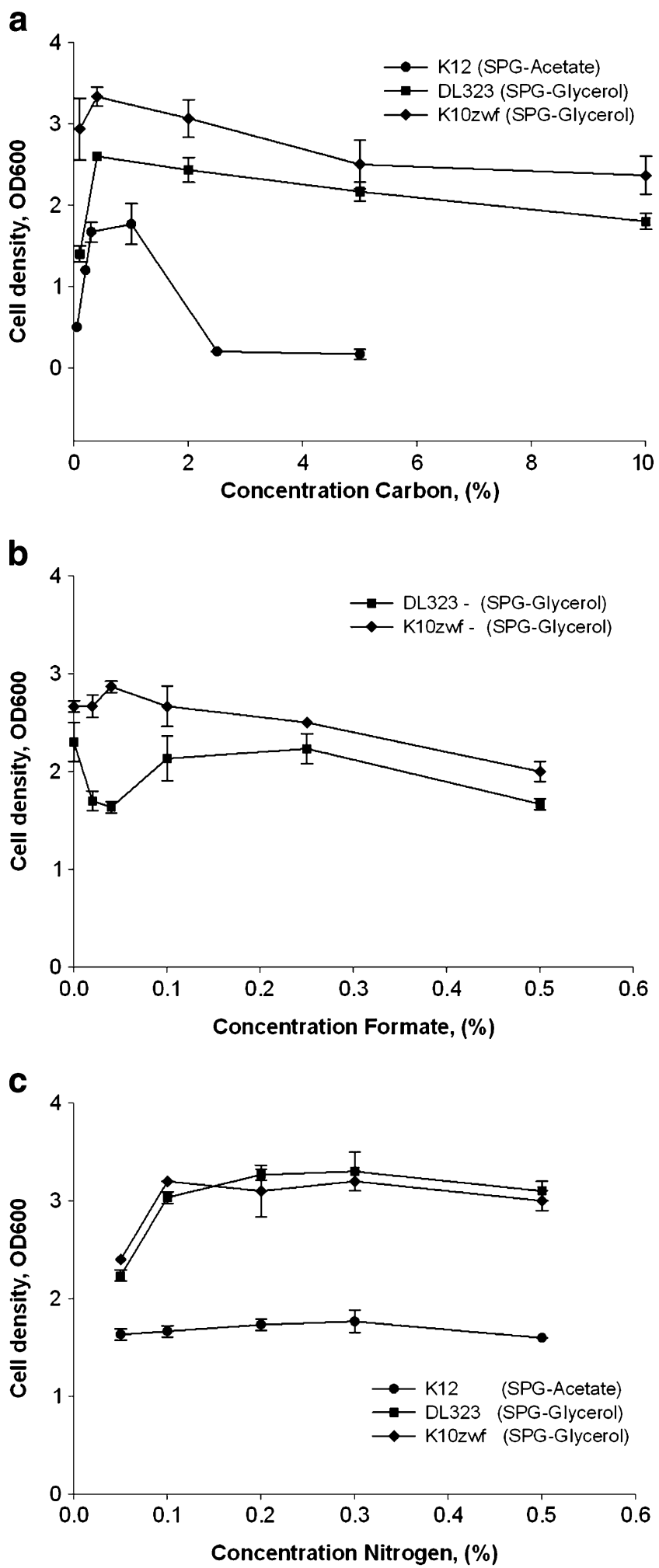

flux in the first step of the TCA cycle and the overall TCA cycle has increased flux in this mutant compared to the wildtype (Zhao et al. 2004; Nicolas et al. 2007). For growth in acetate, however, the flux through the TCA cycle decreases but the glyoxylate shunt compensates with a corresponding increase in flux for the $z w f$ mutant compared to the wild type.
Fig. 2 Yields of various $E$. coli strains as a function of various carbon and nitrogen sources. a Yields of $E$. coli (K12, DL323 and K10zwf) in aerobic batch culture in SPG minimal media as a function of varying acetate $(0.05 \%, 0.2 \%, 0.3 \%, 1 \%, 2.5 \%, 5 \% w / v)$ for $\mathrm{K} 12$ and varying glycerol $(0.1 \%, 0.4 \%, 2 \%, 5 \%, 10 \%$ w/v) for K10zwf and DL323 in the presence of $0.2 \%$ ammonium sulfate. b Yields of E. coli (K10zwf and DL323) in aerobic batch culture in SPG minimal media as a function of varying sodium formate $(0 \%, 0.02 \%, 0.04 \%, 0.1 \%, 0.25 \%, 0.5 \% w / v)$ in the presence of $0.4 \%$ glycerol and $0.2 \%$ ammonium sulfate and trace metals. c Yields of E. coli (K12, DL323, and K10zwf) in aerobic batch culture in SPG minimal media as a function of varying ammonium sulfate $(0.05 \%, 0.1 \%, 0.2 \%, 0.3 \%, 0.5 \% \mathrm{w} / \mathrm{v})$ in the presence of $0.3 \%$ acetate (K12), 0.4\% glycerol (K10zwf and DL323) and trace metals

The carbon flux increases for the early steps of gluconeogensis (Zhao et al. 2004). The overall effect of this carbon flux redistribution is that the zwf mutation does not adversely affect cell growth but grows comparably as the wildtype, in agreement with our results here.

The growth characteristics of the $\mathrm{sdh} / \mathrm{mdh}$ mutant (DL323) on glycerol are comparable to that of the wildtype and the $z w f$ mutant, but growth on acetate M9 is weakened compared to wildtype and the $z w f$ mutant. This can also be rationalized as follows. Disruption of the TCA cycle in the double mutant of malate dehydrogenase and succinate dehydrogenase should eliminate the fraction of oxaloacetate generated through the TCA cycle. The anaplerotic PEP carboxylase is then expected to exclusively generate oxaloacetate (LeMaster and Kushlan 1996; Fischer and Sauer 2003). For growth on acetate as the sole carbon source, the glyoxylate shunt is the only pathway allowing growth on acetyl Co-A (Cozzone 1998). In the absence of sdh, succinate cannot be converted to fumarate, and therefore malate. In turn, malate cannot be converted to oxaloacetate in the absence of mdh. In addition, the PEP carboxylase expression levels are downregulated in acetate (Oh et al. 2002). Consequently, sdh/mdh mutants should barely grow on acetate. This is in agreement with our observations.

Labeling patterns useful for NMR applications are obtained in the aromatic ring of NMPs derived from K12 bacterial cultures, and yet the labeling pattern within the ribose ring is less desirable because adjacent carbon sites

Table 3 Yields of labeled ribonucleotides

\begin{tabular}{llll}
\hline $\begin{array}{l}\text { Strain/carbon } \\
\text { source/media }\end{array}$ & $\begin{array}{l}\text { Gram wet cells in } \\
500 \mathrm{ml} \text { culture }\end{array}$ & $\begin{array}{l}\text { rNMPs/mg in } \\
500 \mathrm{ml} \text { culture }\end{array}$ & $\begin{array}{c}\text { rNMP/ } \\
\text { dNMP }\end{array}$ \\
\hline K12 acetate in SPG & 1.6 & 20.7 & 1.7 \\
$\begin{array}{l}\text { DL323 glycerol in } \\
\quad 3 P G, \text { with formate }\end{array}$ & 3.2 & 8.4 & 2.1 \\
$\begin{array}{c}\text { DL323 glycerol in } \\
\text { LMR, with formate }\end{array}$ & 2.8 & 11.9 & 5.9 \\
$\begin{array}{l}\text { K10zwf glycerol in } \\
\quad 2 P G, \text { with formate }\end{array}$ & 2.2 & 25 & 6.7 \\
K10zwf glycerol in & 2.2 & 33.9 & 7.2 \\
$\quad$ SPG, no formate & & & \\
\hline
\end{tabular}



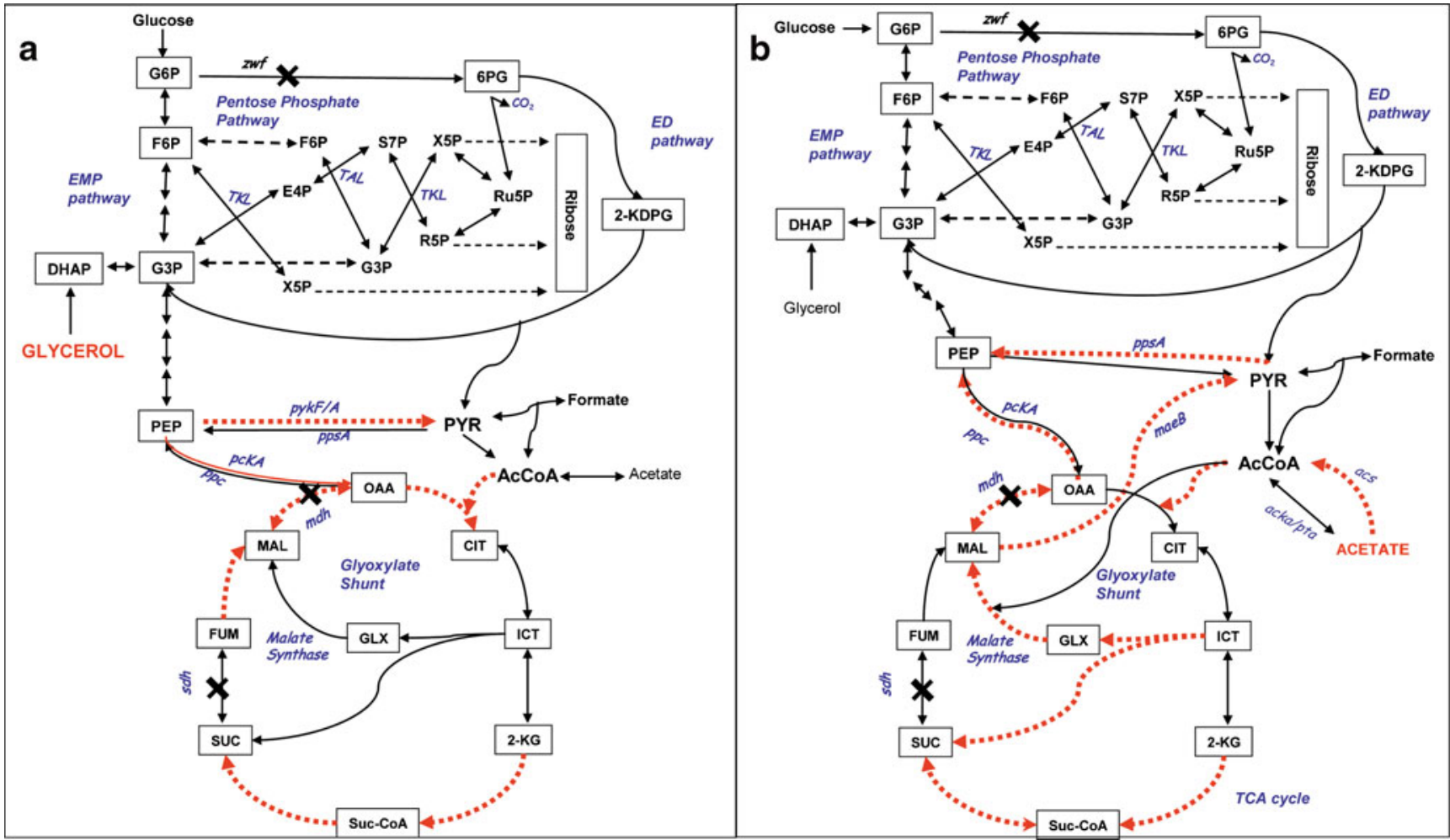

Fig. 3 Prediction of expression levels of central metabolic pathway genes in glycerol and acetate derived from gene expression profiling and metabolic flux data (Oh and Liao 2000; Oh et al. 2002) and from protein expression data (Peng and Shimizu 2003). Red (dotted) lines represents upregulation of individual genes in either glycerol or acetate grown cells relative to glucose grown cells. The $X$ represent mutations of E. coli strains (zwf: K10-1516; and $m d h$ and $s d h$ : DL323) used in this study. a The relative expression levels of the central metabolic pathway genes in glycerol relative to those in glucose. For example the expression levels of $p y k F, p y k A$ and $m d h$ are high. b The relative expression levels of the central metabolic pathway genes in acetate relative to those in glucose. The expression levels of $p p s A, m a e B, p p c$, malate synthase, acs, $m d h$ were up-regulated. G6P glucose-6- phosphate, F6P fructose-6-phosphate, DHAP dihydroxyacetone phosphate, G3P glyceraldehyde-3-phosphate, TKL transketolases, TAL transaldolases, F6P fructose-6-phosphate, E4P erythrose-4-phosphate, $S 7 P$ septulose-7-phosphate, $R 5 P$ ribose-5-phosphate, $R 45 P$ ribulose-5phosphate, $X 5 P$ xylose-5-phosphate, 2-KDPG 2-keto-3-deoxygluconate-6-phosphate, $P E P$ phosphoenolpyruvate, $O A A$ oxaloacetate, $G L X$ glyoxylate, $P Y R$ pyruvate, $A c C o A$ acetyl-coenzyme A, CIT citrate, ICT isocitrate, 2-KG -2-keto gluterate, $S U C$ succinate, FUM fumerate, $M A L$ malate, EMP pathway Embden-Meyerhoff-Parnas pathway, $E D$ pathway Entner-Doudoroff, pyk pyruvate kinase, ppsA phosphoenolpyruvate synthetase, $m d h$ malate dehydrogenase, $s d h$ succinate dehydrogenase, acs acetyl co-enzymeA synthetase, $p p c$ phosphoenolpyruvate carboxylase, $p c k A$ phosphoenolypyruvate kinase are labeled in the ribose ring (Hoffman and Holland 1995). The large scalar J-couplings within these labeled sites lead to unwanted reduction of resolution and signal intensity in NMR experiments. Some of these undesirable labeling patterns are absent in NMPs derived from K10zwf bacterial cultures (Johnson et al. 2006; Dayie and Thakur, 2010). Yet until now, it was unclear how well K10zwf grows on acetate or glycerol. Previous studies were carried out using mostly glucose and acetate (Fischer and Sauer 2003; Zhao et al. 2004; Nicolas et al. 2007).

The NMPs derived from K10zwf cultures do not have some of the deficiencies of those obtained from K12. Nonetheless, the aromatic moiety of the NMPs extracted from K10zwf and K12 cultures still suffer from the scrambling of isotopic label in the aromatic ring due to the efficiency of the TCA cycle. E. coli strain DL323, deficient in the two TCA cycle enzymes sdh and mdh, limits the dilution of labeling via the TCA cycle. Again, until now, the extent to which DL323 E. coli cells grow on acetate or glycerol had not been fully characterized. The studies reported herein should therefore benefit those interested in harnessing the potential of these $E$. coli strains to make selective labels for NMR structural studies.

In summary, growth of the three E. coli strains K10zwf, DL323 and K12 in glycerol is best done in LMR whereas growth of K10zwf and K12 in acetate is best done in either LMR or SPG media. M9 is not recommended for any of the $E$. coli strains tested in either glycerol, or glycerol and formate, or acetate. One can obtain $24-66 \mathrm{mg}$ of total ${ }^{13} \mathrm{C}$ labeled rNMPs, per 1,000 $\mathrm{ml}$ culture, which is sufficient to make labeled NMR samples at a cost of $\$ 200-\$ 400$ per sample. E. coli is likely to remain an organism of choice for incorporation of isotopic labels for making labeled RNA for biophysical studies. 
Acknowledgments This work was supported in part by the NanoBiotechnology Award and the National Institutes of Health grant GM077326 to TKD, and JNS is a recipient of a Percy Julian Fellowship (NSF grant CHE0746446) and an HHMI undergraduate fellowship.

Open Access This article is distributed under the terms of the Creative Commons Attribution Noncommercial License which permits any noncommercial use, distribution, and reproduction in any medium, provided the original author(s) and source are credited.

\section{References}

Batey RT, Inada M, Kujawinski E, Puglisi JD, Williamson JR (1992) Preparation of isotopically labeled ribonucleotides for multidimensional nmr spectroscopy of RNA. Nucleic Acids Res 20:4515-4523

Batey RT, Battiste JL, Williamson JR (1995) Preparation of isotopically enriched RNAs for heteronuclear NMR. Methods Enzymol 261:300-322

Byron D (1975) Microbial growth on C1 compounds. In: Ousby JC (ed) Proceedings of the International Symposium on Microbial Growth on C1-Compounds. Society of Fermentation Technology, Japan

Canonaco F, Hess TA, Heri S, Wang T, Szyperski T, Sauer U (2001) Metabolic flux response to phosphoglucose isomerase knock-out in Escherichia coli and impact of overexpression of the soluble transhydrogenase UdhA. FEMS Microbiol Lett 204:247-252

Clowes R (1968) In: Hayes W (ed) Experiments in microbial genetics. Wiley, New York

Cozzone AJ (1998) Regulation of acetate metabolism by protein phosphorylation in enteric bacteria. Annu Rev Microbiol 52:127-164

Dayie KT (2008) Key labeling technologies to tackle sizeable problems in RNA structural biology. Int J Mol Sci 9:1214-1240

Dayie TK, Thakur CS (2010) Site-specific labeling of nucleotides for making RNA for high resolution NMR studies using an E. coli strain disabled in the oxidative pentose phosphate pathway. $\mathrm{J}$ Biomol NMR 47:19-31

Feist AM, Henry CS, Reed JL, Krummenacker M, Joyce AR, Karp PD, Broadbelt LJ, Hatzimanikatis V, Palsson BØ (2007) A genome-scale metabolic reconstruction for Escherichia coli K-12 MG1655 that accounts for 1260 ORFs and thermodynamic information. Mol Syst Biol 3:121

Fischer E, Sauer U (2003) Metabolic flux profiling of Escherichia coli mutants in central metabolism using GC-MS. Eur J Biochem 270:880-891

Fraenkel DG (1968) Selection of Escherichia coli mutants lacking glucose-6-phosphate dehydrogenase or gluconate-6-phosphate dehydrogenase. J Bacteriol 95:1267-1271

Hansen EJ, Juni E (1979) Properties of mutants of Escherichia coli lacking malic dehydrogenase and their revertants. J Biol Chem 254:3570-3575

Hines JV, Landry SM, Varani G, Tinoco I (1994) Carbon-proton scalar couplings in RNA - 3D heteronuclear and 2D isotope - edited NMR of a C-13 labeled extra-stable hairpin. J Am Chem Soc 116:5823-5831

Hoffman DW, Holland JA (1995) Preparation of C-13-labeled ribonucleotides using acetate as an isotope source. Nucleic Acids Res 23:3361-3362

Hoogstraten CG, Johnson JE (2008) Metabolic labeling: taking advantage of bacterial pathways to prepare spectroscopically useful isotope patterns in proteins and nucleic acids. Concepts Magn Reson Part A 32A:34-55

Johnson JE, Hoogstraten CG (2008) Extensive backbone dynamics in the GCAA RNA tetraloop analyzed using ${ }^{13} \mathrm{C}$ NMR spin relaxation and specific isotope labeling. $\mathrm{J}$ Am Chem Soc 130:16757-16769
Johnson JE, Julien KR, Hoogstraten CG (2006) Alternate-site isotopic labeling of ribonucleotides for NMR studies of ribose conformational dynamics in RNA. J Biomol NMR 35:261-274

Latham MR, Brown DJ, McCallum SA, Pardi A (2005) NMR methods for studying the structure and dynamics of RNA. Chembiochem 6:1492-1505

Lemaster DM, Richards FM (1982) Preparative scale isolation of isotopically labeled amino acids. Anal Biochem 122:238-247

LeMaster DM, Kushlan DM (1996) Dynamical mapping of E. coli thioredoxin via C-13 NMR relaxation analysis. J Am Chem Soc 118:9255-9264

Liu M, Durfee T, Cabrera JE, Zhao K, Jin DJ, Blattner FR (2005) Global transcriptional programs reveal a carbon source foraging strategy by Escherichia coli. J Biol Chem 280:15921-15927

Lu K, Miyazaki Y, Summers MF (2010) Isotope labeling strategies for NMR studies of RNA. J Biomol NMR 46:113-125

Milligan JF, Uhlenbeck OC (1989) Synthesis of small RNAs using T7 RNA polymerase. Methods Enzymol 180:51-62

Nicolas C, Kiefer P, Letisse F, Krömer J, Massou S, Soucaille P, Wittmann C, Lindley ND, Portais JC (2007) Response of the central metabolism of Escherichia coli to modified expression of the gene encoding the glucose-6-phosphate dehydrogenase. FEBS Lett 581:3771-3776

Nikonowicz EP (2001) Preparation and use of ${ }^{2} \mathrm{H}$-labeled RNA oligonucleotides in nuclear magnetic resonance studies. Methods Enzymol 338:320-341

Oh MK, Liao JC (2000) Gene expression profiling by DNA microarrays and metabolic fluxes in Escherichia coli. Biotechnol Prog $16: 278-286$

Oh MK, Rohlin L, Kao KC, Liao JC (2002) Global expression profiling of acetate-grown Escherichia coli. J Biol Chem 277:13175-13183

Paliy O, Gunasekera TS (2007) Growth of E. coli BL21 in minimal media with different gluconeogenic carbon sources and salt contents. Appl Microbiol Biotechnol 73:1169-1172

Paliy O, Bloor D, Brockwell D, Gilbert P, Barber J (2003) Improved methods of cultivation and production of deuteriated proteins from $E$. coli strains grown on fully deuteriated minimal medium. J Appl Microbiol 94:580-586

Peng L, Shimizu K (2003) Global metabolic regulation analysis for Escherichia coli K12 based on protein expression by 2 dimensional electrophoresis and enzyme activity measurement. Appl Microbiol Biotechnol 61(2):163-178

Ponchon L, Dardel F (2007) Recombinant RNA technology: the tRNA scaffold. Nat Meth 4:571-576

Ponchon L, Beauvais G, Nonin-Lecomte S, Dardel F (2009) A generic protocol for the expression and purification of recombinant RNA in Escherichia coli using a tRNA scaffold. Nat Protoc 4:947-959

Rowley DL, Pease AJ, Wolf RE Jr (1991) Genetic and physical analyses of the growth rate-dependent regulation of Escherichia coli zwf expression. J Bacteriol 173:4660-4667

Sambrook J, Russell D (2001) Molecular cloning: a laboratory manual. Cold Spring Harbor Laboratory, Cold Spring Harbor

Soupene E, van Heeswijk WC, Plumbridge J, Stewart V, Bertenthal D, Lee H, Prasad G, Paliy O, Charernnoppakul P, Kustu S (2003) Physiological studies of Escherichia coli strain MG1655: growth defects and apparent cross-regulation of gene expression. J Bacteriol 185:5611-5626

Studier F (2005) Protein production by auto-induction in high-density shaking cultures. Protein Expr Purif 41:207-234

Tyler RC, Sreenath HK, Singh S, Aceti DJ, Binginan CA, Markley JL, Fox BG (2005) Auto-induction medium for the production of $U$ N-15 - and U-C-13, U-N-15 -labeled proteins for NMR screening and structure determination. Protein Expr Purif 40:268-278

Zhao J, Baba T, Mori H, Shimizu K (2004) Effect of zwf gene knockout on the metabolism of Escherichia coli grown on glucose or acetate. Metab Eng 6:164-174 